\title{
The Advantage of Antibody Cocktails for Targeted Alpha Therapy Depends on Specific Activity
}

\author{
Jordan B. Pasternack ${ }^{1}$, Jason D. Domogauer ${ }^{1}$, Alisha Khullar ${ }^{1}$, John M. Akudugu ${ }^{2}$, and Roger W. Howell ${ }^{1}$ \\ ${ }^{I}$ Division of Radiation Research, Department of Radiology, New Jersey Medical School Cancer Center, Rutgers, State University of \\ New Jersey, Newark, New Jersey; and ${ }^{2}$ Division of Radiobiology, Department of Medical Imaging and Clinical Oncology, Faculty of \\ Health Sciences, Stellenbosch University, Tygerberg, South Africa
}

Nonuniform dose distributions among disseminated tumor cells can be a significant limiting factor in targeted a therapy. This study examines how cocktails of radiolabeled antibodies can be formulated to overcome this limitation. Methods: Cultured MDA-MB-231 human breast cancer cells were treated with different concentrations of a cocktail of 4 fluorochrome-conjugated monoclonal antibodies. The amount of each antibody bound to each cell was quantified using flow cytometry. A spreadsheet was developed to "arm" the antibodies with any desired radionuclide and specific activity, calculate the absorbed dose to each cell, and perform a Monte Carlo simulation of the surviving fraction of cells after exposure to cocktails of different antibody combinations. Simulations were performed for the a-particle emitters ${ }^{211} \mathrm{At},{ }^{213} \mathrm{Bi}$, and ${ }^{225} \mathrm{Ac}$. Results: Activity delivered to the least labeled cell can be increased by $200 \%-400 \%$ with antibody cocktails, relative to the best-performing single antibody. Specific activity determined whether a cocktail or a single antibody achieved greater cell killing. With certain specific activities, cocktails outperformed single antibodies by a factor of up to 244 . There was a profound difference ( $\leq 16$ logs) in the surviving fraction when a uniform antibody distribution was assumed and compared with the experimentally observed nonuniform distribution. Conclusion: These findings suggest that targeted a therapy can be improved with customized radiolabeled antibody cocktails. Depending on the antibody combination and specific activity of the radiolabeled antibodies, cocktails can provide a substantial advantage in tumor cell killing. The methodology used in this analysis provides a foundation for pretreatment prediction of tumor cell survival in the context of personalized cancer therapy.

Key Words: radioimmunotherapy; targeted alpha therapy; antibody cocktails; isolated tumor cells; disseminated tumor cells; flow cytometry; Monte Carlo; radionuclide; specific activity; alpha particle

J Nucl Med 2014; 55:2012-2019

DOI: 10.2967/jnumed.114.141580

$\mathbf{R}$ adioimmunotherapy of cancer is a modality that uses radiolabeled antibodies to target, and locally irradiate, tumor cells (1). Despite the promise of radioimmunotherapy, only 2 agents have thus far been approved by the U.S. Food and Drug Administration for therapeutic use. Although complex safety and regulatory issues

Received Apr. 14, 2014; revision accepted Aug. 22, 2014.

For correspondence or reprints contact: Roger W. Howell, Division of Radiation Research, Department of Radiology, Rutgers-New Jersey Medical School Cancer Center, F-1208, 205 S. Orange Ave., Newark, NJ 07103.

E-mail: rhowell@rutgers.edu

Published online Oct. 27, 2014.

COPYRIGHT (c) 2014 by the Society of Nuclear Medicine and Molecular Imaging, Inc. have played a role in slowing the introduction of new agents, the limited number is also due in part to difficulties in adequately irradiating all the cancer cells; there are many interacting and complex reasons for this. One important yet under-investigated physiologic hindrance is that for a given antigen target, there is a nonuniform distribution in the number of binding sites per cell among any given population of cancer cells (2-4). Consequently, after administration of a radiolabeled antibody, some cancer cells may have little or no antibody bind to their surface and therefore may not be lethally irradiated. The specific activity of the radioimmunoconjugate plays an important role in this issue (4). This is critical for microscopic disease, in which therapeutically beneficial cross-irradiation from neighboring radiolabeled cancer cells may be limited (2-6).

Microscopic disease arises principally from disseminated tumor cells (DTCs) that have been shed from primary tumors and localize in lymph nodes and organs such as bone marrow $(7,8)$. DTCs can progress to micrometastases through a complex series of steps (7). The presence of DTCs is a significant risk factor of a reduced life expectancy in patients $(7,8)$, prompting changes to the histologic terminology used for staging; single cells or clusters of tumor cells with diameter of less than $0.2 \mathrm{~mm}$ have been defined as isolated tumor cells and are distinguished from micrometastases (0.2$2.0 \mathrm{~mm}$ ) (9). A key goal for targeted radionuclide therapy is to develop strategies to sterilize DTCs. A necessary prerequisite for sterilizing DTCs is to overcome the nonuniform activity distributions that are inherent in targeted radionuclide therapies. This is particularly important in the context of radioimmunotherapy with radionuclides that emit short-range $\alpha$ particles, often referred to as targeted $\alpha$ therapy.

Cocktails of radiolabeled monoclonal antibodies have been used in an effort to overcome problems associated with nonuniform targeting of tumor cells (10-13). Such cocktails have met with both failure and success (1). Pagel et al. enhanced the uniformity of activity distribution among B-cell lymphoma xenografts with a cocktail of 3 radiolabeled antibodies; however, the absolute uptake of the antibody combination was less than that of the single antibody with the highest uptake (14). In contrast, Milenic et al. showed that ${ }^{213} \mathrm{Bi}$-labeled antibody cocktails can improve therapeutic efficacy against human colon carcinoma xenografts (13). These different outcomes suggest that approaches are needed to predict, on a caseby-case basis, the relative advantage of using cocktails of radiolabeled antibodies versus a single radiolabeled antibody for radioimmunotherapy. The present study examined some aspects of this relative advantage with antibodies targeted to a human breast cancer cell line. A Monte Carlo simulation was used to arm the antibodies with different $\alpha$-particle emitters and determine cell survival after 
different treatments. This technique can guide pretreatment prediction of tumor cell survival for radioimmunotherapy with a given cocktail of radiolabeled antibodies.

\section{MATERIALS AND METHODS}

\section{Cell Culture}

The cell culture protocol followed that of Akudugu et al. $(6,15,16)$. Briefly, MDA-MB-231-luc-D3H1 (MDA-MB-231) human breast cancer cells (Caliper Life Sciences) were grown in minimum essential medium (Cellgro catalog number 10-010-CV). The medium was supplemented with heat-inactivated $10 \%$ fetal calf serum (Life Technologies catalog number 10438-026), 2 mM L-glutamine (Cellgro catalog number 25-005-CV), 100 units of penicillin per milliliter, $100 \mu \mathrm{g}$ of streptomycin per milliliter (Cellgro catalog number 30-002-CI), and $10 \mathrm{mg}$ of nonessential amino acids per milliliter (Cellgro catalog number 25-025-CI). Cells were grown as monolayers in $175 \mathrm{~cm}^{2}$ flasks $\left(37^{\circ} \mathrm{C}, 5 \% \mathrm{CO}_{2}-95 \%\right.$ air, humidified) and were used for experiments (passages 29-34) at 70\%-90\% confluence.

\section{Antibody Selection and Labeling}

Candidate antibodies were selected on the basis of published expression profiles of potential molecular targets for MDA-MB-231 cells (17-19). Four lead antibodies were selected. Three were obtained from BioLegend: APC anti-epidermal growth factor receptor (EGFR) (AY13), Pacific Blue anti-CD-73 (AD2), and phycoerythrin (PE) antiCD-44 (BJ18). One was obtained from R\&D Systems: AF-488 antiCD-44 (691534). Additional antibodies were tested but not selected because of a relatively lower antigen density: Pacific Blue anti-EpCAM (9C4) and PE anti-CD-221 (1H7) from BioLegend; AF-700 anti-GLUT1 (202915) from R\&D Systems; PE anti-EGFR (528), AF-405 anti-EGFR (R-1), and PE anti-Tag-72 (B72.3) from Santa Cruz; and PerCP anti-EGFR (LA22) from Millipore.

Cells were trypsinized ( $0.5 \%$ trypsin/ethylenediaminetetraacetic acid), resuspended in medium, syringed using a 21 -gauge needle, counted, and centrifuged for $5 \mathrm{~min}$ at $27^{\circ} \mathrm{C}$ and $1,040 \mathrm{rpm}$. The supernatant was removed, the cells were resuspended in medium supplemented with only penicillin-streptomycin (incubation medium), and 3-mL aliquots containing $10^{6}$ cells were transferred to $5-\mathrm{mL}$ round-bottomed tubes. All tubes were centrifuged for $5 \mathrm{~min}$ at $27^{\circ} \mathrm{C}$ and $1,040 \mathrm{rpm}$ and the supernatant removed. The cells were resuspended in $100 \mu \mathrm{L}$ of incubation medium containing various combinations of fluorochrome-labeled monoclonal antibodies. The concentration of each antibody in a given combination was equivalent. A $1 \mu \mathrm{g} / \mathrm{mL}$ treatment, for example, contained a $1 \mu \mathrm{g} / \mathrm{mL}$ concentration of each antibody in the combination. The tubes were shielded from light and placed on a hematology mixer for $2 \mathrm{~h}$ at $37^{\circ} \mathrm{C}$ in $5 \% \mathrm{CO}_{2}$ and $95 \%$ air. After the labeling, the cells were washed in complete medium, resuspended in $1.0 \mathrm{~mL}$ of phosphatebuffered saline, and analyzed using a LSR II flow cytometer (BD Biosciences). Minimally, 300,000 cells were analyzed for each sample. The flow cytometry data were analyzed with FlowJo, version 8 (Treestar Software). Apparent debris in the forward scatter-side scatter plots was gated out, and compensation was performed.

\section{Determination of Number of Molecules of Each Antibody on Each Cell}

Flow cytometric analysis revealed a wide distribution of antibody uptake, with apparent lognormal-like characteristics. The fluorescence intensity of a given cell is directly proportional to the amount of bound antibody. Accordingly, Quantum Simply Cellular calibration beads (Bangs Laboratories, catalog number 815B) were used to calibrate the relationship between the number of antibody molecules bound to a cell and cellular fluorescence (4). Calibrations were performed according to the manufacturer's instructions, and calibration coefficients were determined. Importantly, calibrations were conducted for each color within each experiment. No historical calibrations were used.

\section{Simulation of Antibody Radiolabeling and Determination of Distribution of Cellular Absorbed Dose}

The compensated flow cytometric fluorescence data for all cells in each sample population were copied from FlowJo and pasted into an Excel spreadsheet (Microsoft), and the number of molecules of each antibody on each cell was calculated using the calibration coefficients. Each antibody was then armed with ${ }^{211} \mathrm{At}$, initially assuming a specific activity of $4.25 \times 10^{15} \mathrm{~Bq} / \mathrm{mol}$ (4) (211 At-trastuzumab, $4.4-100 \mathrm{kBq} / \mu \mathrm{g}$; molecular weight, $\left.1.6 \times 10^{5} \mathrm{~g} / \mathrm{mol}\right)$ and that each antibody delivers an initial activity $\mathrm{A}_{\mathrm{i}} \mathrm{Bq}$ to the $\mathrm{i}^{\text {th }}$ cell that is directly proportional to the number of molecules of that antibody that is bound to the cell. Additional specific activities were studied as per Tables 1 and 2 . The time-integrated activity coefficient ã was assumed to be $36,180 \mathrm{~s}$, the physical half-life of ${ }^{211} \mathrm{At}$. The cellular $\mathrm{S}$ value was taken to be $4.14 \times 10^{-2} \mathrm{~Gy} \mathrm{~Bq}^{-1} \mathrm{~s}^{-1}$, which is the absorbed dose to the cell nucleus per decay of ${ }^{211} \mathrm{At}$ and its daughter ${ }^{211} \mathrm{Po}$ on the surface of a spheric cell with radius $5 \mu \mathrm{m}$ and nuclear radius $3 \mu \mathrm{m}$ (20). With these

\section{TABLE 1}

Dependence of Relative Advantage on Specific Activity When Cells Are Treated with Radiolabeled Ab2 vs. Cocktail of Radiolabeled Antibodies

\begin{tabular}{|c|c|c|c|}
\hline \multirow[b]{2}{*}{ Relative advantage } & \multicolumn{3}{|c|}{$\begin{array}{c}\text { Specific activity } \\
\rightarrow \rightarrow \rightarrow \text { increasing } \rightarrow \rightarrow \rightarrow\end{array}$} \\
\hline & $A$ & $\mathrm{~B}$ & C \\
\hline$\frac{\mathrm{SF}\left({ }^{211} \mathrm{At}-\mathrm{Ab} 2\right)}{\mathrm{SF}\left({ }^{(211} \mathrm{At}-\mathrm{Ab}+{ }^{211} \mathrm{At}-\mathrm{Ab} 3+{ }^{211} \mathrm{At}-\mathrm{Ab} 4\right)}$ & $1.26 \pm 0.02$ & $2.67 \pm 0.44$ & $1.38 \pm 0.62$ \\
\hline$\frac{\mathrm{SF}\left({ }^{213} \mathrm{Bi}-\mathrm{Ab} 2\right)}{\mathrm{SF}\left({ }^{213} \mathrm{Bi}-\mathrm{Ab} 2+{ }^{213} \mathrm{Bi}-\mathrm{Ab} 3+{ }^{213} \mathrm{Bi}-\mathrm{Ab} 4\right)}$ & $2.20 \pm 0.98$ & $0.65 \pm 0.25$ & $0.54 \pm 0.15$ \\
\hline$\frac{\mathrm{SF}\left(^{225} \mathrm{Ac}-\mathrm{Ab} 2\right)}{\mathrm{SF}\left({ }^{225} \mathrm{Ac}-\mathrm{Ab} 2+{ }^{225} \mathrm{Ac}-\mathrm{Ab} 3+{ }^{225} \mathrm{Ac}-\mathrm{Ab} 4\right)}$ & $2.59 \pm 0.57$ & $1.53 \pm 1.04$ & $1.13 \pm 0.75$ \\
\hline
\end{tabular}

Specific activity of ${ }^{211}$ At-antibodies is $9.25 \times 10^{13} \mathrm{~Bq} \mathrm{~mol}^{-1}$ for $\mathrm{A}, 9.25 \times 10^{14} \mathrm{~Bq} \mathrm{~mol}^{-1}$ for B, and $9.25 \times 10^{15} \mathrm{~Bq} \mathrm{~mol}^{-1}$ for C in

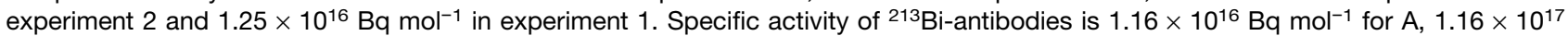
$\mathrm{Bq} \mathrm{mol}{ }^{-1}$ for $\mathrm{B}$, and $1.56 \times 10^{17} \mathrm{~Bq} \mathrm{~mol}^{-1}$ for $\mathrm{C}$. Specific activity of ${ }^{225} \mathrm{Ac}$-antibodies is $8.14 \times 10^{12} \mathrm{~Bq} \mathrm{~mol}^{-1}$ for $\mathrm{A}, 8.14 \times 10^{13} \mathrm{~Bq} \mathrm{~mol}^{-1}$ for $\mathrm{B}$, and $1.14 \times 10^{14} \mathrm{~Bq} \mathrm{~mol}^{-1}$ for $\mathrm{C}$. Ratio $>1$ implies cocktail is more lethal than single antibody. Ratios are average of 2 experiments. SEs are noted. Ab2 alone contains Ab2 $\left(3 \mu \mathrm{g} \mathrm{mL}^{-1}\right)$, cocktail contains Ab2 $(1 \mu \mathrm{g} \mathrm{mL}-1)$, Ab3 $(1 \mu \mathrm{g} \mathrm{mL}-1)$, and Ab4 (1 $\left.\mu \mathrm{g} \mathrm{mL} \mathrm{L}^{-1}\right)$. Specific activity in column $B$ is cited in literature for given radionuclide $(4,21,22)$. Column $A$ is 10 -fold reduction of that specific activity, and column $\mathrm{C}$ is specific activity required to result in about 10 survivors of analyzed population of 300,000 cells. 
TABLE 2

Dependence of Relative Advantage on Specific Activity When Cells Are Treated with Radiolabeled Ab4 vs. Cocktail of Radiolabeled Antibodies

\begin{tabular}{|c|c|c|c|}
\hline \multirow[b]{2}{*}{ Relative advantage } & \multicolumn{3}{|c|}{$\begin{array}{r}\text { Specific activity } \\
\rightarrow \rightarrow \rightarrow \text { increasing } \rightarrow \rightarrow \rightarrow\end{array}$} \\
\hline & A & B & $\mathrm{C}$ \\
\hline$\frac{\mathrm{SF}\left({ }^{211} \mathrm{At}-\mathrm{Ab} 4\right)}{\mathrm{SF}\left({ }^{(211} \mathrm{At}-\mathrm{Ab} 4+{ }^{211} \mathrm{At}-\mathrm{Ab} 1+{ }^{211} \mathrm{At}-\mathrm{Ab} 3\right)}$ & $0.34 \pm 0.02$ & $2.83 \pm 1.35$ & $244 \pm 69$ \\
\hline$\frac{\mathrm{SF}\left({ }^{213} \mathrm{Bi}-\mathrm{Ab} 4\right)}{\mathrm{SF}\left({ }^{213} \mathrm{Bi}-\mathrm{Ab} 4+{ }^{213} \mathrm{Bi}-\mathrm{Ab} 1+{ }^{213} \mathrm{Bi}-\mathrm{Ab} 3\right)}$ & $5.10 \pm 2.80$ & $131 \pm 88$ & $230 \pm 88$ \\
\hline$\frac{\left.\mathrm{SF}{ }^{225} \mathrm{Ac}-\mathrm{Ab} 4\right)}{\mathrm{SF}\left({ }^{225} \mathrm{Ac}-\mathrm{Ab}+{ }^{225} \mathrm{Ac}-\mathrm{Ab} 1+{ }^{225} \mathrm{Ac}-\mathrm{Ab} 3\right)}$ & $1.62 \pm 0.64$ & $90.3 \pm 60.9$ & $167 \pm 57$ \\
\hline \multicolumn{4}{|c|}{ 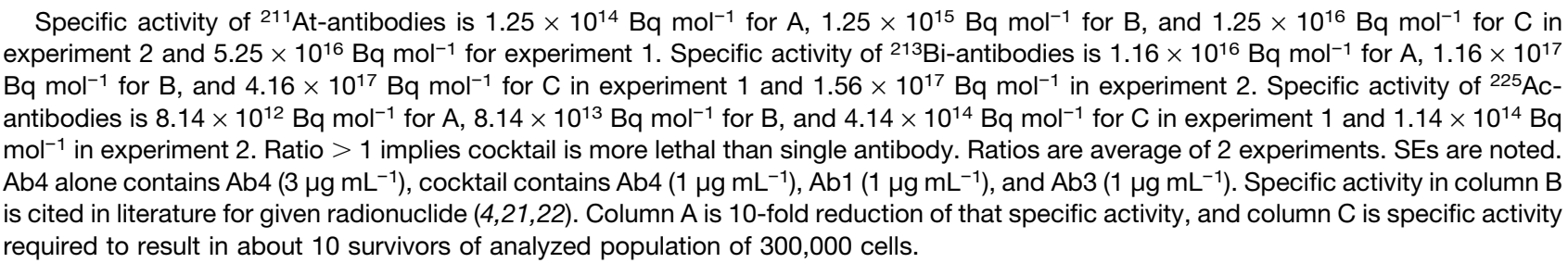 } \\
\hline
\end{tabular}

assumptions, the absorbed dose $D_{i}$ to the $i^{\text {th }}$ cell in each sample population was calculated for each antibody according to $D_{i}=\tilde{a} A_{i} S$. This resulted in a distribution of absorbed doses for each sample population.

The same approach was adopted for 2 additional $\alpha$-particle-emitting radionuclides, ${ }^{213} \mathrm{Bi}$ and ${ }^{225} \mathrm{Ac}$. For ${ }^{213} \mathrm{Bi}$, specific activity was $1.16 \times$ $10^{17} \mathrm{~Bq} / \mathrm{mol}(21)$, ã was $3,864 \mathrm{~s}$, and $\mathrm{S}$ was $5.32 \times 10^{-2} \mathrm{~Gy} \mathrm{~Bq}^{-1} \mathrm{~s}^{-1}(20)$. For ${ }^{225} \mathrm{Ac}$, specific activity was $8.14 \times 10^{13} \mathrm{~Bq} / \mathrm{mol}(22)$, ã was $1.21 \times$ $10^{6} \mathrm{~s}$, and $\mathrm{S}$ was $1.65 \times 10^{-1} \mathrm{~Gy} \mathrm{~Bq}^{-1} \mathrm{~s}^{-1}(20)$. Daughter radionuclides were included in the cellular $\mathrm{S}$ values. Additional specific activities were studied as per Tables 1 and 2 .

\section{Monte Carlo Modeling of Surviving Fraction (SF) of Breast Cancer Cells}

The Monte Carlo simulation developed by Akudugu et al. $(6,15)$, modified to account for specific activity and absorbed dose, was used to predict the SF of the cells for each antibody treatment assuming a mean lethal dose $\mathrm{D}_{37}$ of $1 \mathrm{~Gy}$. This approach calculates the probability that a given cell survives based on the absorbed dose contributions from each radiolabeled antibody on that particular cell and then uses a Monte Carlo approach to determine whether the cell lives or dies (15). Simulations were also conducted for all possible combinations of antibody treatments to determine the SF of cells in each case. SF was calculated in two ways: one that used the antibody uptakes for each cell as measured by flow cytometry and one in which every cell in the population is assumed to contain the same amount of antibody, which corresponds to the mean antibody uptake of the population. To study the impact of specific activity on the relative advantage of using cocktails of antibodies versus single antibodies, simulations were conducted with progressively increasing specific activities of $\alpha$-emitterlabeled antibodies until only about 10 cells survived. This arbitrary point was selected to avert the difficulties in identifying the specific activity that drives the stochastic result to zero survivors.

\section{RESULTS}

Preliminary flow cytometric analyses were performed for the candidate monoclonal antibodies to determine their relative fluorescence intensity profiles after treating MDA-MB-231 cells. Antibodies that demonstrated relatively low binding (based on their fluorescence intensity profiles) were excluded from further study.
On the basis of these findings, an antibody cocktail of 4 fluorescencelabeled antibodies (Ab1-Ab4) was prepared:

$$
\begin{aligned}
& \mathrm{Ab} 1=\mathrm{APC} \text { anti-EGFR (AY13) } \\
& \mathrm{Ab} 2=\mathrm{AF}-488 \text { anti-CD-44 (691534) } \\
& \mathrm{Ab} 3=\text { Pacific Blue anti-CD-73 (AD2) } \\
& \mathrm{Ab} 4=\text { PE anti-CD-44 (BJ18) }
\end{aligned}
$$

$\mathrm{Ab} 2$ and Ab4 target different epitopes of CD-44; preliminary studies showed that their binding was additive. Targeting multiple epitopes that do not overlap is a strategy that is showing promise in the clinic to address the heterogeneity of receptor expression among targeted cell populations (23). Fluorescence histograms corresponding to binding of the 4 individual antibodies to MDAMB-231 cells after treatment with an antibody cocktail containing

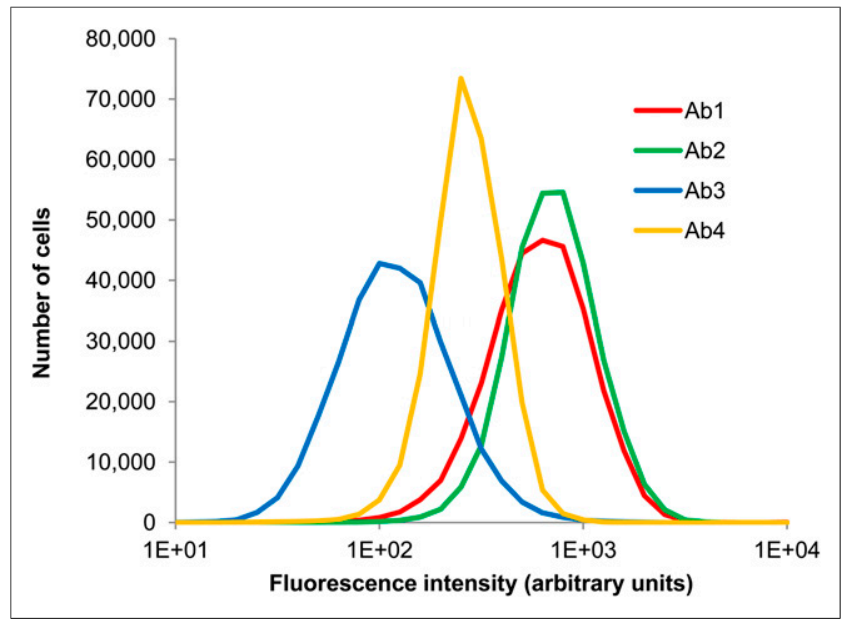

FIGURE 1. Fluorescence histograms showing distribution of uptake of Ab1, Ab2, Ab3, and Ab4 by MDA-MB-231 cells. Cells were labeled with cocktail of these 4 antibodies, concentration of each being $1 \mu \mathrm{g} / \mathrm{mL}$. Data represent a combination of 3 experiments with the exception of Ab3 (2 experiments). 


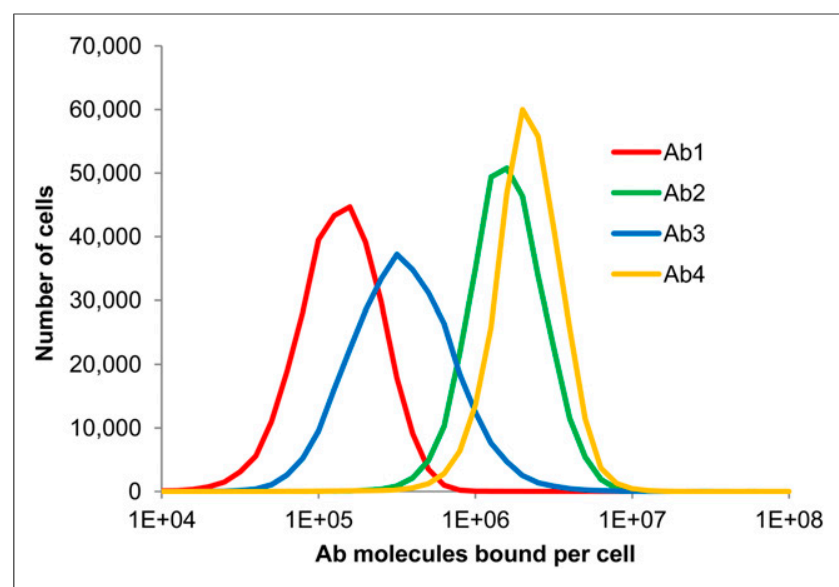

FIGURE 2. Histograms depicting distribution of number of molecules of $A b 1, A b 2, A b 3$, and Ab4 bound to MDA-MB-231 cells. Cells were labeled with cocktail of these 4 antibodies, concentration of each being $1 \mu \mathrm{g} / \mathrm{mL}$. Data represent combination of 3 experiments with exception of Ab3 (2 experiments). Molecules per cell were determined from fluorescence intensity values based on calibrations with Quantum Simply Cellular beads.

$1 \mu \mathrm{g} / \mathrm{mL}$ each of Ab1, Ab2, Ab3, and Ab4 are shown in Figure 1. The uptake of each antibody resembles a lognormal distribution. Although cellular binding of a given antibody is directly proportional to fluorescence, the relative fluorescence values between the different fluorochromes of the 4 antibodies did not reflect the relative number of antibodies bound to the cells. Figure 2 shows the distribution of each antibody on the same cell population, after calibration with Quantum Simply Cellular beads. It can be seen that the second highest fluorescence intensity is Ab1, but after calibration $\mathrm{Ab} 1$ is actually the least expressed of the 4 antigens. This highlights the importance of calibrating every experiment, a practice that also accounts for any changes in flow cytometer settings. The mean number of antibody molecules per cell, as a

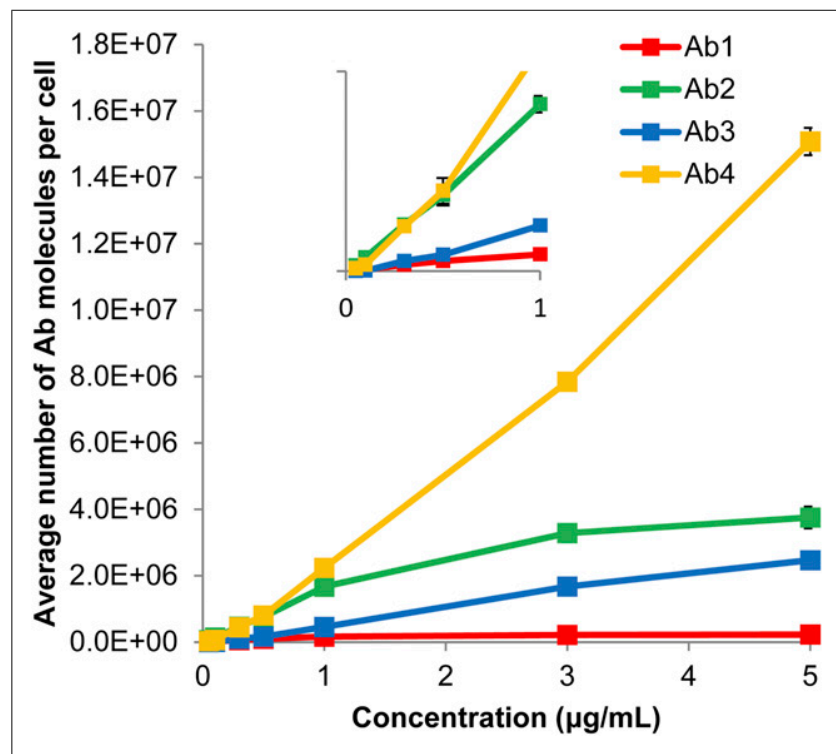

FIGURE 3. Mean number of antibody molecules bound per cell with $\mathrm{SE}(n=3$; for Ab3, $n=2)$ as function of concentration of antibodies in cocktail. SEs fit within symbols. Inset zooms in on low-concentration region $(<1 \mu \mathrm{g} / \mathrm{mL})$ to demonstrate linearity in this region. function of treatment concentration, is shown in Figure 3 for each constituent of the cocktail. Binding of $\mathrm{Ab} 1, \mathrm{Ab} 2$, and $\mathrm{Ab} 3$ begins to saturate at approximately $1 \mu \mathrm{g} / \mathrm{mL}$.

Figure 4 demonstrates the absorbed dose distribution for the MDA-MB-231 cell nuclei after the antibodies were armed with ${ }^{211}$ At. Select combinations of the cocktail are depicted. The distributions after exposure to pre- and post-saturation concentrations of 0.5 and $3.0 \mu \mathrm{g} / \mathrm{mL}$, respectively, are shown in Figures $4 \mathrm{~A}$ and $4 \mathrm{~B}$, respectively. In both cases, the absorbed dose to the cell population increases as the available antibodies within the cocktail increases. Of note is the subpopulation of cells that receives very low absorbed doses from Ab4 (Fig. 4C); this distribution is not of

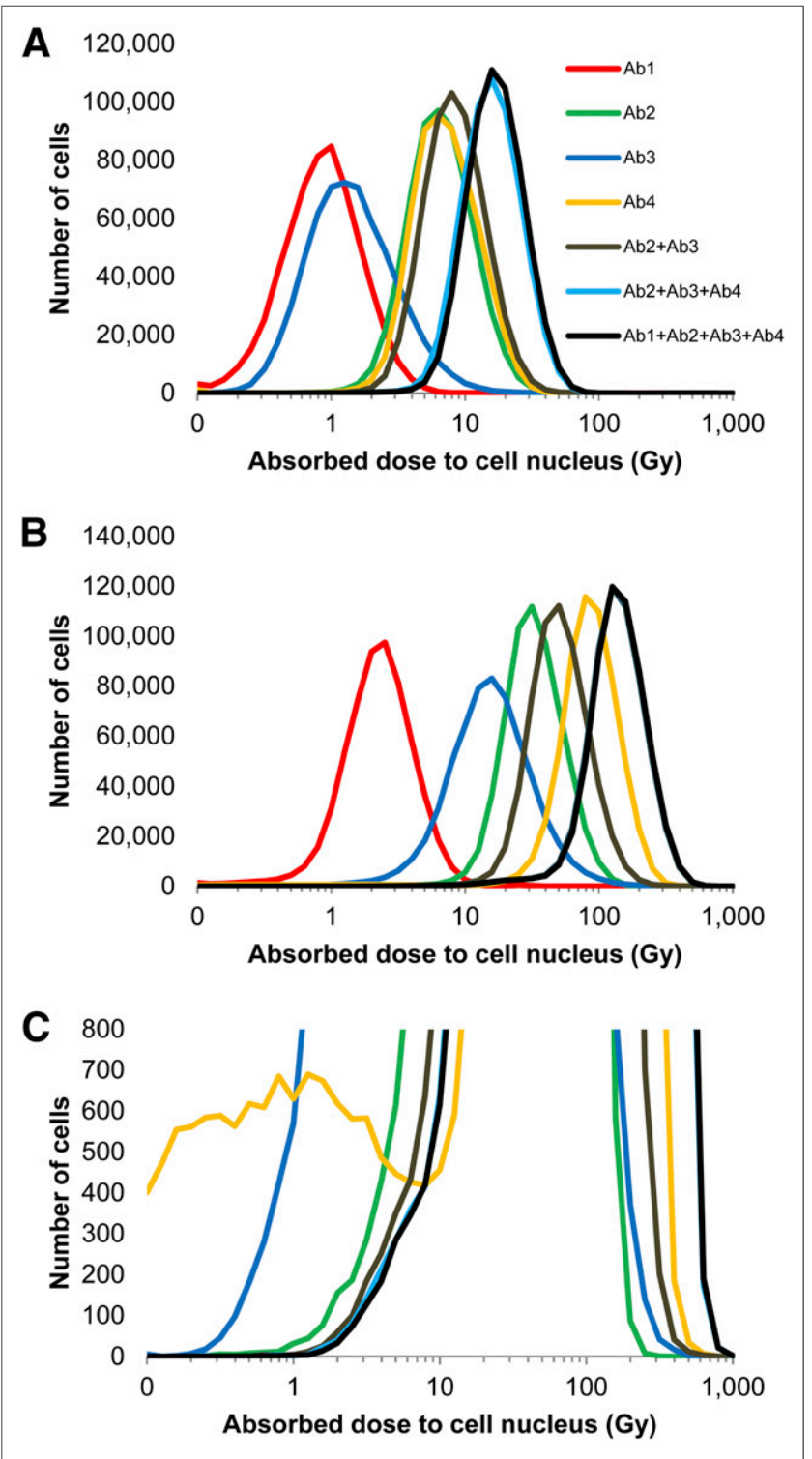

FIGURE 4. ( $\mathrm{A}$ and $\mathrm{B}$ ) Histograms depicting distributions of absorbed dose to MDA-MB-231 cells exposed to different permutations of antibody cocktail at $0.5 \mu \mathrm{g} / \mathrm{mL}$ (A) and $3.0 \mu \mathrm{g} / \mathrm{mL}$ (B). (C) Rescaled vertical axis for $3.0 \mu \mathrm{g} / \mathrm{mL}$ plot to emphasize a subpopulation of cells with low Ab4 binding. Antibodies were armed with ${ }^{211} \mathrm{At}$ at specific activity of $4.25 \times 10^{15} \mathrm{~Bq} / \mathrm{mol}$. Data represent combination of 3 experiments, with exception of Ab3 (2 experiments). 
lognormal character and further highlights the complexity of nonuniform antigen expression.

The SF of cells treated with each combination of radiolabeled antibodies in the quadruple-antibody cocktail was simulated (Fig. 5). Ab2 was the most effective single antibody at all concentrations (Fig. 5A). Adding any one of the remaining 3 antibodies decreased the SF at all concentrations (Fig. 5B). At $5.0 \mu \mathrm{g} / \mathrm{mL}$, the best-performing double-antibody cocktail, Ab2 and Ab3, resulted in an additional log of cell kill when compared with the best single antibody. The same can be seen at $0.5 \mu \mathrm{g} / \mathrm{mL}$, except here the best double-antibody cocktail was Ab2 and Ab4 (antiCD-44 BJ18). It is interesting that the best double-antibody cocktail was $\mathrm{Ab} 2$ and $\mathrm{Ab} 4$ at low concentrations but $\mathrm{Ab} 2$ and $\mathrm{Ab} 3$ at high concentrations, at which binding sites were saturating (Fig. $3)$. When either remaining antibody was added to the best postsaturation double cocktail (Ab2 and Ab3), the SF decreased at all concentrations (Fig. 5C). The triplet combination of Ab1, Ab2, and $\mathrm{Ab} 4$ performed approximately as well as the best postsaturation double-antibody cocktail at all concentrations. Additionally,
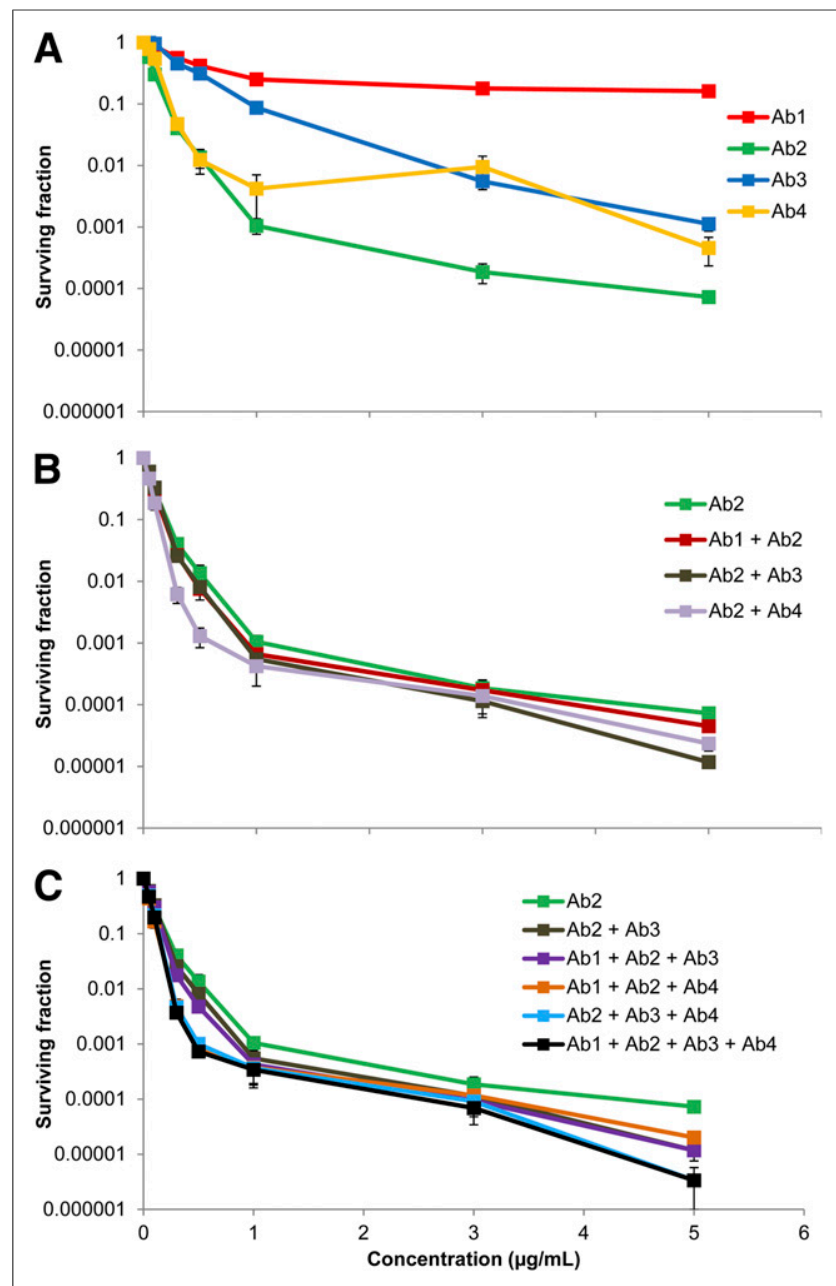

FIGURE 5. Mean SF of MDA-MB-231 cells as function of antibody concentration for different combinations of ${ }^{211} \mathrm{At}$-labeled antibodies (specific activity, $4.25 \times 10^{15} \mathrm{~Bq} / \mathrm{mol}$ ), highlighting effect of single antibodies (A), double-antibody cocktails (B), and triple- and quadrupleantibody cocktails $(C)$. Error bars represent SEM $(n=3$; for Ab3, $n=2)$. the quadruple-antibody cocktail performed as well as or better than all triple cocktails at all tested concentrations.

The dependence of SF on antibody distribution was assessed for the different cocktail combinations at $1.0 \mu \mathrm{g} / \mathrm{mL}$. The SFs derived from experimentally measured antibody distributions were compared with those from assumed uniform antibody distributions, in which each cell received the mean absorbed dose to the respective populations (Fig. 6). The SF for the uniform distribution was significantly lower than the respective SF for the nonuniform experimental distribution for all combinations studied. As the number of the antibodies in the cocktail increased, so did the discrepancy between the SFs for the uniform distribution and the nonuniform experimental distribution.

Last, the dependence of cell killing on the specific activity of the ${ }^{211}$ At-labeled antibodies was studied. In this context, the efficacy of antibody cocktails versus a single antibody was compared by holding the total antibody concentration constant $(3.0 \mu \mathrm{g} / \mathrm{mL})$ while varying the specific activity of the ${ }^{211}$ At-labeled antibodies. Accordingly, single-antibody treatments were analyzed at $3.0 \mu \mathrm{g} / \mathrm{mL}$, and antibody cocktails comprised 3 antibodies, each at $1.0 \mu \mathrm{g} / \mathrm{mL}$. Cocktails were compared with $\mathrm{Ab} 2$ alone (Fig. 7A) and $\mathrm{Ab} 4$ alone (Fig. 7B), because they emerged as the most effective singleantibody treatments (Fig. 5A). Similar analyses were performed for ${ }^{213} \mathrm{Bi}$ and ${ }^{225} \mathrm{Ac}$ (Tables 1 and 2).

\section{DISCUSSION}

Radioimmunotherapy is a promising cancer therapy but remains a relatively under-investigated and under-utilized treatment modality. This is particularly true in the context of targeting DTCs, a growing concern in cancer therapy $(8,24,25)$. One major constraint that has limited its advancement is insufficient targeting of the entire tumor cell population. We hypothesize that rational selection of the constituents of a cocktail of radiolabeled antibodies can improve targeting of the entire population of tumor cells and thereby increase the percentage of cells that are lethally irradiated.

With the exception of Ab4, the mean levels of antibody binding to MDA-MB-231 cells began to saturate with increasing concentration

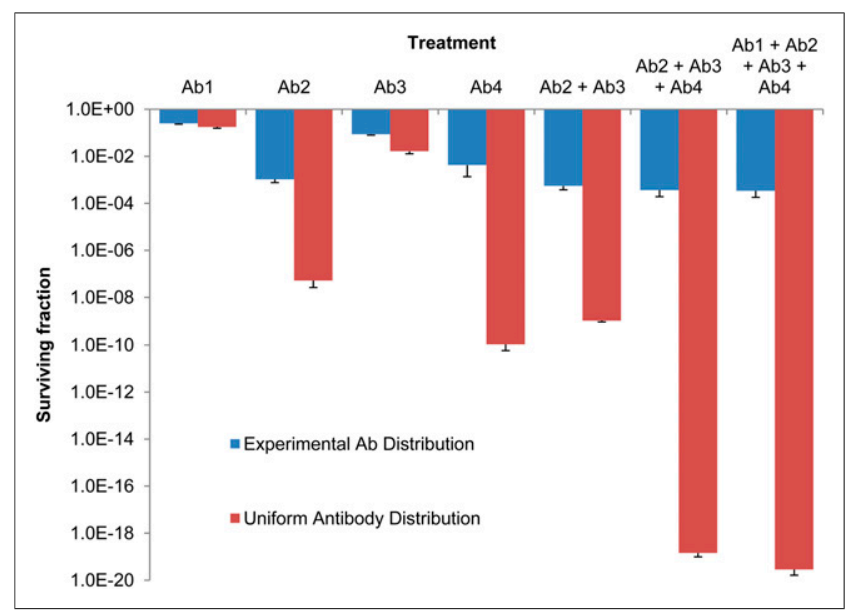

FIGURE 6. Dependence of SF on distribution of antibody binding among targeted cells and on constituents of antibody cocktail (concentration, $1.0 \mu \mathrm{g} / \mathrm{mL}$ ). Antibodies were armed with ${ }^{211} \mathrm{At}$ at specific activity of $4.25 \times 10^{15} \mathrm{~Bq} / \mathrm{mol}$. Mean SF with SE are displayed ( $n=3$; for Ab3, $n=2$ ). Large differences in SF arise when experimentally measured distributions are compared with assumed uniform distribution. 


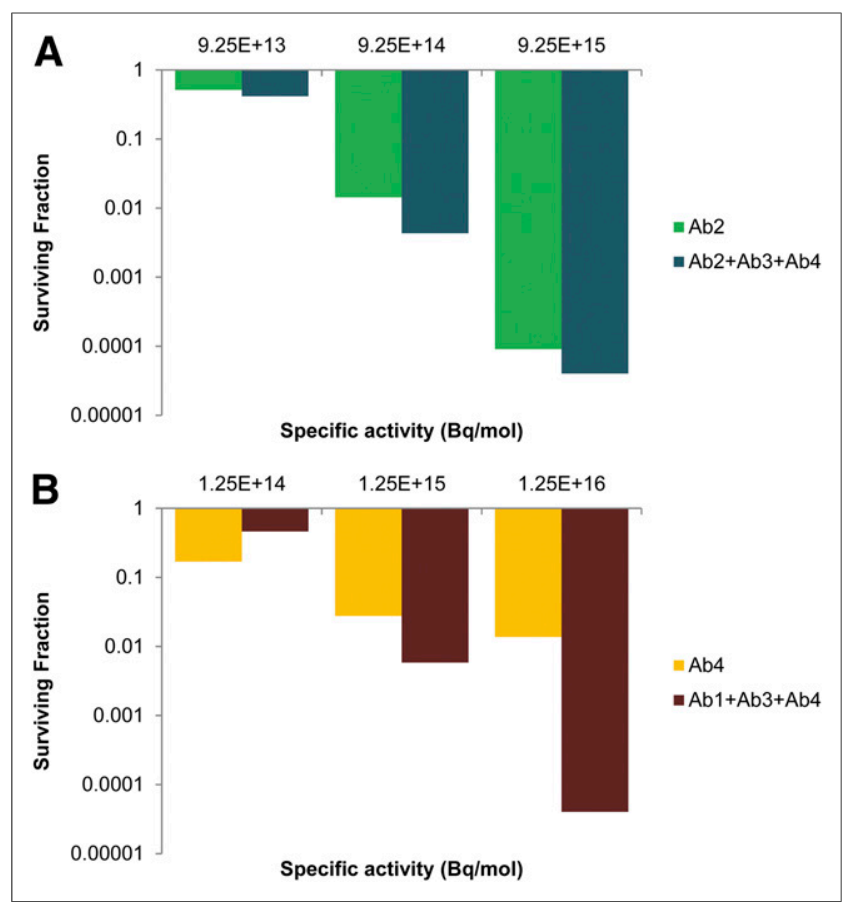

FIGURE 7. Comparison of cell killing with single antibodies vs. cocktails of antibodies when total antibody concentration is held constant and specific activity of ${ }^{211} \mathrm{At}$-labeled antibodies is varied. Concentration is $3.0 \mu \mathrm{g} / \mathrm{mL}$ for single antibodies and $1.0 \mu \mathrm{g} / \mathrm{mL}$ for antibodies in cocktails, such that all treatments have total antibody concentration of 3.0 $\mu \mathrm{g} / \mathrm{mL}$. Cocktails were compared with Ab2 (A) and Ab4 (B). Data shown are from 1 experiment; results were similar in other experiments (Tables 1 and 2).

at about $1.0 \mu \mathrm{g} / \mathrm{mL}$ (Fig. 3). This is reflected in the survival curves that correspond to single-antibody treatments (Fig. 5A); note that these curves begin to saturate at about $1.0 \mu \mathrm{g} / \mathrm{mL}$ as well. This parallels observations made by Akudugu et al. when MDA-MB231 cells were treated with doxorubicin, daunomycin, and ${ }^{210}$ Po-citrate (16). The saturation in the Ab4 curve occurred despite the linear increase in mean antibody binding over the entire concentration range studied. As shown in Figure 4C, this can be attributed to insufficient targeting of a small subpopulation of cells that have low antibody binding. These cells receive much lower absorbed doses than the other cells in the population, which dramatically increases their probability of survival. This also explains why Ab2 attains a higher degree of cell kill than Ab4 (Fig. 5A), despite the apparent advantage of Ab4 in Figure 3.

It is interesting to note the changes in the absorbed dose distribution both when the concentration of a given ${ }^{211}$ At-labeled antibody was increased and when additional antibodies were added to the cocktail. Comparison of Figures $4 \mathrm{~A}$ and $4 \mathrm{~B}$ shows that increasing the concentration from 0.5 to $3 \mu \mathrm{g} / \mathrm{mL}$ narrowed the distribution, a phenomenon observed by Akudugu et al. (16). As more antibodies were added to the cocktail, at both presaturation $(0.5 \mu \mathrm{g} / \mathrm{mL}$, Fig. $4 \mathrm{~A})$ and postsaturation ( $3 \mu \mathrm{g} / \mathrm{mL}$, Fig. 4B) concentrations, the shape of the absorbed dose distribution curve became taller and narrower (Fig. 4).

At the presaturation antibody concentration, $0.5 \mu \mathrm{g} / \mathrm{mL}$, the least irradiated cells in the single-antibody treatments received absorbed doses ranging from 0.1 to $1.0 \mathrm{~Gy}$. The least irradiated cells treated with the different combinations of the cocktail received larger doses, with the triple- and quadruple-cocktail treatments delivering 3-4 Gy (Fig. 4A). This difference is significant as indicated by the increased cell killing that can be achieved, at this concentration, when cells are treated with the antibody cocktails compared with a single antibody (Fig. 5A). Similar observations could be made at the postsaturation concentration of $3 \mu \mathrm{g} / \mathrm{mL}$, albeit at considerably higher absorbed doses (Figs. 4B and 5B). The triple-antibody cocktail had an absorbed dose distribution almost identical to the quadruple-antibody cocktail (Fig. 4B). At this concentration, it appears that $\mathrm{Ab} 1$ had little effect when combined with the 3 other antibodies. However, Ab1 had a slightly more observable contribution at the presaturation concentration (Fig. 4A).

To focus on the impact of antibody distribution among the target cell population, dosimetry calculations assumed cell surface binding of antibodies and no biologic clearance from the cell or internalization within the cell. Anti-CD44, anti-EGFR, and antiCD73 have been described to internalize on binding to cell surface receptors (26-29). This would increase the $S$ values (i.e., dose per decay) beneficially by up to a factor of 6 depending on whether the radionuclide is shuttled to the nucleus $(20,30)$. However, more importantly, the biologic clearance may be affected adversely, particularly in the case of ${ }^{211} \mathrm{At}$, because halogens are metabolized by cells once internalized. Similarly, the decay of ${ }^{225} \mathrm{Ac}$ to its daughters may result in their departure from the cell, which would have a substantial impact on the dose delivered. Although these factors can play a major role in the distribution of absorbed dose among the targeted population, they are moot in the absence of an initial targeting distribution that is therapeutically viable.

Based on the shape of the distributions of fluorescence, and thus antibody molecules on the population of labeled cells, it appears that the binding of anti-EGFR, anti-CD-44, anti-CD-73, and antiCD-44 on the surface of MDA-MB-231 cells was reasonably lognormal (Figs. 1-2). Anti-CD-44 deviated from lognormal quite remarkably at the low expression end of the spectrum (Fig. 4C). This was also observed for anti-CD20 and anti-TP3 in other cell lines (2). Absorbed dose estimates often assume a uniform distribution by simply considering the mean. Figure 6 compares the response of MDA-MB-231 cells with cocktails of ${ }^{211}$ At-labeled antibodies when absorbed dose distributions were calculated on the basis of the observed lognormal distribution versus an assumed uniform distribution. Far more cell killing was afforded by the uniform distribution than the experimental lognormal distributions, with up to a 16-log difference. This indicates that the lognormal antigen distribution among a cancer cell population is a substantial hurdle to overcome in radioimmunotherapy because it can be difficult to eradicate isolated tumor cells. This emphasizes the need to assess the distribution of each antigen to be targeted $(2,4,16)$. Furthermore, cocktails of antibodies can improve targeting and thus cell killing with radioimmunotherapy, enhancing the effectiveness of the therapy (Fig. 6). The role of radiolabeled antibody cocktails is not limited to treating DTCs but is also important when treating very small micrometastases for which lognormal activity distributions of $\alpha$ emitters can affect the response of the cell population $(20,31)$. As the size of the micrometastasis increases, the nonuniformity of the activity distribution may be dominated by issues related to the absence of sufficient penetration into the core (32).

Specific activity is an important determinant in radioimmunotherapy (33). However, the role of specific activity in determining the relative advantage of cocktails of radiolabeled antibodies relative to single radiolabeled antibodies has not been explored. Figure 7 provides insight into the critical role that specific activity plays 
in this assessment. When cell survival after treatment with ${ }^{211} \mathrm{At}-$ labeled $\mathrm{Ab} 2$ alone is compared with a cocktail of ${ }^{211} \mathrm{At}$-labeled $\mathrm{Ab} 2, \mathrm{Ab} 3$, and Ab4 at a fixed total antibody concentration of $3 \mu \mathrm{g} / \mathrm{mL}$, it is apparent that the added benefit of the cocktail was modest regardless of the specific activity (Fig. 7A). The relative advantage, defined as the ratio of the SFs resulting from the different treatments, was only 1.26-, 2.67 -, and 1.38 -fold for specific activities of $9.25 \times 10^{13}, 9.25 \times 10^{14}$, and $1.25 \times 10^{16} \mathrm{~Bq} / \mathrm{mol}$, respectively (Table 1). However, when ${ }^{211}$ At-labeled Ab4 alone is compared with a cocktail of ${ }^{211}$ At-labeled Ab1, Ab3, and Ab4 at a fixed total antibody concentration of $3 \mu \mathrm{g} / \mathrm{mL}$, the relative advantage could be substantial (Fig. 7B). Relative advantages of 0.34-, 2.83-, and 244-fold were obtained for specific activities of $1.25 \times 10^{14}, 1.25 \times 10^{15}$, and $1.25 \times 10^{16} \mathrm{~Bq} / \mathrm{mol}$, respectively (Table 2). The large enhancement at the highest specific activity can be attributed to the increased capacity of Ab1 and Ab3 to contribute to the sterilization of the small population of cells with low Ab4 antigen density (Fig. 4C) when the specific activity was raised. This high specific activity is achievable (4), and values as high as $1 \mathrm{GBq} / \mathrm{mg}\left(\sim 1.6 \times 10^{17} \mathrm{~Bq} / \mathrm{mol}\right)$ for ${ }^{211}$ At-trastuzumab have been obtained (34). If limited to specific activities of only $1.25 \times 10^{14} \mathrm{~Bq} / \mathrm{mol}$, then Ab4 alone is preferred. Similar results could be seen when the antibodies were labeled with ${ }^{213} \mathrm{Bi}$ or ${ }^{225}$ Ac. For the mid-level and higher specific activities when Ab4 was used as the baseline for comparison, the cocktail was highly advantageous (Table 2). When Ab2 was used as the baseline, the cocktail could have a modest benefit depending on the specific activity (Table 1).

The work described here provides a foundation for developing pretreatment prediction of DTC survival for radioimmunotherapy in a cancer patient. The approach can potentially be used as an aid to select constituents of a cocktail of radiolabeled antibodies for a given cancer in a given patient. One possible approach would be to obtain a marrow biopsy containing DTCs, which could then be subjected to labeling with fluorochrome-labeled antibodies and analyzed by flow cytometry. Monte Carlo modeling with the resulting fluorescence distribution data could reveal the most effective antibody cocktail in terms of predicted cell killing. The Monte Carlo approach also allows modeling with a single radionuclide or combination of radionuclides and with various specific activities. Alternatively, a cocktail of fluorescence-labeled antibodies could be injected into the patient before capture of the biopsy containing DTCs, followed by flow cytometric and Monte Carlo analysis. Investigation of these approaches in preclinical models is warranted.

\section{CONCLUSION}

Radioimmunotherapy has great potential for the treatment of cancer, especially against DTC populations, which account for a large percentage of therapy failures. A current shortcoming of radioimmunotherapy, particularly in the context of targeted $\alpha$ therapy, is the nonuniform distribution of antigen expression among cancer cell populations, which can result in inadequate tumor cell targeting and consequent delivery of sublethal absorbed radiation doses. The approach described here entails the use of multiplexed antibody cocktails to improve targeting and enhance killing of cancer cells to overcome the hurdle that nonuniform antigen expression can represent in targeted $\alpha$ therapy. It was demonstrated that the specific activity of the radiolabeled antibody can play a central role in determining the relative advantage of using antibody cocktails versus single antibodies. The methods described here provide guidance for personalized targeted $\alpha$ therapy of cancer.

\section{DISCLOSURE}

The costs of publication of this article were defrayed in part by the payment of page charges. Therefore, and solely to indicate this fact, this article is hereby marked "advertisement" in accordance with 18 USC section 1734. This work was supported in part by NIH/NCI grant 5R25CA019536-32 and New Jersey Health Care Foundation grant PC85-12. Jason Domogauer was supported by a predoctoral fellowship grant from the New Jersey Commission on Cancer Research (DFHS13PPCO17). This work is the subject of U.S. patent applications 14/444,391 filed July 28, 2014, and 13/ 953,414 filed July 29, 2013. The content of this article is solely the responsibility of the authors and does not necessarily represent the official views of the New Jersey Health Care Foundation, the National Cancer Institute, or the National Institutes of Health. No other potential conflict of interest relevant to this article was reported.

\section{REFERENCES}

1. Sharkey RM, Goldenberg DM. Cancer radioimmunotherapy. Immunotherapy. 2011;3:349-370.

2. Kvinnsland Y, Stokke T, Aurlien E. Radioimmunotherapy with alphaparticle emitters: microdosimetry of cells with a heterogeneous antigen expression and with various diameters of cells and nuclei. Radiat Res. 2001;155:288-296.

3. Neti PV, Howell RW. Log normal distribution of cellular uptake of radioactivity: implications for biologic responses to radiopharmaceuticals. J Nucl Med. 2006; 47:1049-1058.

4. Akabani G, Carlin S, Welsh P, Zalutsky MR. In vitro cytotoxicity of ${ }^{211}$ Atlabeled trastuzumab in human breast cancer cell lines: effect of specific activity and HER2 receptor heterogeneity on survival fraction. Nucl Med Biol. 2006; 33:333-347.

5. Sgouros G, Scheinberg DA. Treatment of leukemia with radiolabeled monoclonal antibodies. Cancer Treat Res. 1993;68:23-64.

6. Akudugu JM, Howell RW. Flow cytometry-assisted Monte Carlo simulation predicts clonogenic survival of cell populations with lognormal distributions of radiopharmaceuticals and anticancer drugs. Int J Radiat Biol. 2012;88: 286-293.

7. Wan L, Pantel K, Kang Y. Tumor metastasis: moving new biological insights into the clinic. Nat Med. 2013;19:1450-1464.

8. Hayashi N, Yamauchi H. Role of circulating tumor cells and disseminated tumor cells in primary breast cancer. Breast Cancer. 2012;19:110-117.

9. Singletary SE, Connolly JL. Breast cancer staging: working with the sixth ed. of the AJCC Cancer Staging Manual. CA Cancer J Clin. 2006;56:37-47; quiz 50-31.

10. Blumenthal RD, Kashi R, Stephens R, Sharkey RM, Goldenberg DM. Improved radioimmunotherapy of colorectal cancer xenografts using antibody mixtures against carcinoembryonic antigen and colon-specific antigen-p. Cancer Immunol Immunother. 1991;32:303-310.

11. Meredith RF, Khazaeli MB, Plott WE, et al. Phase II study of dual ${ }^{131}$ I-labeled monoclonal antibody therapy with interferon in patients with metastatic colorectal cancer. Clin Cancer Res. 1996;2:1811-1818.

12. DeNardo GL, Tobin E, Chan K, Bradt BM, DeNardo SJ. Direct antilymphoma effects on human lymphoma cells of monotherapy and combination therapy with CD20 and HLA-DR antibodies and ${ }^{90}$ Y-labeled HLA-DR antibodies. Clin Cancer Res. 2005; 11:7075s-7079s.

13. Milenic DE, Brady ED, Garmestani K, Albert PS, Abdulla A, Brechbiel MW. Improved efficacy of alpha-particle-targeted radiation therapy: dual targeting of human epidermal growth factor receptor-2 and tumor-associated glycoprotein 72 . Cancer. 2010;116:1059-1066.

14. Pagel JM, Pantelias A, Hedin N, et al. Evaluation of CD20, CD22, and HLA-DR targeting for radioimmunotherapy of B-cell lymphomas. Cancer Res. 2007;67: 5921-5928.

15. Akudugu JM, Howell RW. A method to predict response of cell populations to cocktails of chemotherapeutics and radiopharmaceuticals: validation with daunomycin, doxorubicin, and the alpha particle emitter ${ }^{210} \mathrm{Po}$. Nucl Med Biol. 2012;39:954-961. 
16. Akudugu JM, Neti PVSV, Howell RW. Changes in lognormal shape parameter guide design of patient-specific radiochemotherapy cocktails. J Nucl Med. 2011; 52:642-649.

17. Powell AA, Talasaz AH, Zhang H, et al. Single cell profiling of circulating tumor cells: transcriptional heterogeneity and diversity from breast cancer cell lines. PLoS ONE. 2012;7:e33788.

18. Grover-McKay M, Walsh SA, Seftor EA, Thomas PA, Hendrix MJ. Role for glucose transporter 1 protein in human breast cancer. Pathol Oncol Res. 1998; 4:115-120.

19. Osta WA, Chen Y, Mikhitarian K, et al. EpCAM is overexpressed in breast cancer and is a potential target for breast cancer gene therapy. Cancer Res. 2004;64:5818-5824.

20. Vaziri B, Wu H, Dhawan AP, Du P, Howell RW. MIRD pamphlet no. 25: MIRDcell V2.0 software tool for dosimetric analysis of biologic response of multicellular populations. J Nucl Med. 2014;55:1557-1564.

21. McDevitt MR, Finn RD, Ma D, Larson SM, Scheinberg DA. Preparation of alpha-emitting ${ }^{213} \mathrm{Bi}$-labeled antibody constructs for clinical use. J Nucl Med. 1999;40:1722-1727.

22. McDevitt MR, Ma D, Simon J, Frank RK, Scheinberg DA. Design and synthesis of ${ }^{225}$ Ac radioimmunopharmaceuticals. Appl Radiat Isot. 2002;57:841-847.

23. Koefoed K, Steinaa L, Soderberg JN, et al. Rational identification of an optimal antibody mixture for targeting the epidermal growth factor receptor. MAbs. 2011;3:584-595.

24. Murray NP, Reyes E, Tapia P, et al. Redefining micrometastasis in prostate cancer: a comparison of circulating prostate cells, bone marrow disseminated tumor cells and micrometastasis-implications in determining local or systemic treatment for biochemical failure after radical prostatectomy. Int $J$ Mol Med. 2012;30:896-904.
25. Mathiesen RR, Borgen E, Renolen A, et al. Persistence of disseminated tumor cells after neoadjuvant treatment for locally advanced breast cancer predicts poor survival. Breast Cancer Res. 2012;14:R117.

26. Lee JL, Wang MJ, Chen JY. Acetylation and activation of STAT3 mediated by nuclear translocation of CD44. J Cell Biol. 2009;185:949-957.

27. Wang Q, Villeneuve G, Wang Z. Control of epidermal growth factor receptor endocytosis by receptor dimerization, rather than receptor kinase activation. EMBO Rep. 2005;6:942-948.

28. Stagg J, Divisekera U, McLaughlin N, et al. Anti-CD73 antibody therapy inhibits breast tumor growth and metastasis. Proc Natl Acad Sci USA. 2010;107:1547-1552.

29. Terp MG, Olesen KA, Arnspang EC, et al. Anti-human CD73 monoclonal antibody inhibits metastasis formation in human breast cancer by inducing clustering and internalization of CD73 expressed on the surface of cancer cells. J Immunol. 2013;191:4165-4173.

30. Goddu SM, Howell RW, Rao DV. Cellular dosimetry: absorbed fractions for monoenergetic electron and alpha particle sources and S-values for radionuclides uniformly distributed in different cell compartments. J Nucl Med. 1994;35:303-316.

31. Neti PVSV, Howell RW. Biological response to nonuniform distributions of ${ }^{210}$ Po in multicellular clusters. Radiat Res. 2007;168:332-340.

32. Ballangrud AM, Yang WH, Charlton DE, et al. Response of LNCaP spheroids after treatment with an alpha-particle emitter $\left({ }^{213} \mathrm{Bi}\right)$-labeled anti-prostate-specific membrane antigen antibody (J591). Cancer Res. 2001;61:2008-2014.

33. Wessels BW, Rogus RD. Radionuclide selection and model absorbed dose calculations for radiolabeled tumor associated antibodies. Med Phys. 1984;11:638-645.

34. Lindegren S, Frost S, Back T, Haglund E, Elgqvist J, Jensen H. Direct procedure for the production of ${ }^{211}$ At-labeled antibodies with an epsilon-lysyl-3-(trimethylstannyl) benzamide immunoconjugate. J Nucl Med. 2008;49:1537-1545. 